\title{
Neurosurgical aspects of falls from flat-roofed houses
}

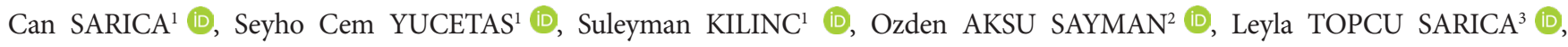 \\ Ilyas DOLAS ${ }^{4}$ (D), Tanin OGUR ${ }^{1} \mathbb{D}$, Arman OZGUNDUZ ${ }^{1}\left(\mathbb{D}\right.$, Necati UCLER $^{1} \mathbb{D}$, Ali OZEN $^{1}$ (D) \\ ${ }^{1}$ Department of Neurosurgery, Adiyaman University Education and Research Hospital, Adiyaman, Turkey. \\ ${ }^{2}$ Department of Public Health, School of Medicine, Istanbul Cerrahpasa University, Istanbul, Turkey. \\ ${ }^{3}$ Department of Anesthesiology and Reanimation, Adiyaman University Education and Research Hospital, Adiyaman, Turkey. \\ ${ }^{4}$ Neurosurgery Clinic, Acibadem Taksim Hospital, Istanbul, Turkey.
}

Corresponding Author: Can SARICA

E-mail: can.sarica@gmail.com

Submitted: 27.08.2020 Accepted: 20.10.2020

\begin{abstract}
Objective: This study analyzed the current incidence and characteristics of neurosurgical injuries after falls from flat-roofed houses in Adiyaman.

Patients and Methods: This retrospective study evaluated data of 31 patients who fell from flat-roofed houses and consulted the neurosurgery unit between January and December 2017 at Adiyaman University Hospital, Turkey. Mann-Whitney U test and Spearman coefficient were used for statistical analysis.

Results: There were 19 male and 12 female patients [mean age, 16.8 (range: $1-78$ ) years; <18 years = 77\%]. The 2017 crude rate of falls in Adiyaman was 5/100,000 cases. Mean fall height was $2.8 \pm 1.0(2-6) \mathrm{m}$. The number of cases is significantly higher in months with temperature $>33^{\circ} \mathrm{C}$ (June-September) than those $<33^{\circ} \mathrm{C}(\mathrm{p}=0.006)$. The most common pathology on initial computed tomography was isolated linear fracture (38\%). Five patients ( 2 cranial, 3 spinal) underwent surgery. All patients, except one, reported no or acceptable symptoms in their first outpatient clinic visit. The overall mortality rate was $0 \%$.

Conclusion: High falls from flat-roofed houses are still a common cause of neurosurgical injury. However, the current incidence in Adiyaman is currently not as high as the rates 20 years ago in Diyarbakir, a neighboring city with similar lifestyles.

Keywords: Fall, Flat-roofed houses, Incidence, Injury, Neurosurgery, Trauma
\end{abstract}

\section{INTRODUCTION}

In hot summer months, the residents of Southeastern Turkey mostly prefer sleeping on the top of flat-roofed houses instead of sleeping inside the house. This is a centuries-old common tradition in the Mesopotamia region that corresponds to Southeastern Turkey, Syria, and Iraq and extends to Kuwait and certain parts of Saudi Arabia. Besides sleeping, the roof of these village houses is a part of daily activities where women dry and store foods; it also serves as a playground for children. This results in a year-long incidence of falls from such roofed houses [1].

Flat-roofed houses are not specific to the Middle East region; in addition, they are commonly encountered in shantytowns worldwide, particularly in South American countries such as Brazil [2] or Asian countries such as Pakistan [3].

Previously, falls from flat-roofed houses were considered the second leading cause of death from accidental injuries in our region [1]. However, the incidence of such fall-related injuries has been drastically declining in the last few years. Therefore, this study aimed to analyze the current incidence and characteristics of fall-related neurosurgical injuries in a Southeastern Turkey city named Adiyaman.

\section{MATERIALS and METHODS}

This was a retrospective study including the prospectively collected data of 31 patients admitted to the emergency department after a fall from flat-roofed houses and consulted to the neurosurgery unit between January 2017 and December 2017 at Adiyaman University Hospital, Adiyaman, Turkey. This hospital is the only tertiary referral trauma center in the entire Adiyaman province with a neurosurgery department. Collected data included age, sex, date, and location of the incident, neurosurgical pathology on the initial computed tomography (CT), height of fall, landing material, reason of fall, the initial Glasgow Coma Scale (GCS) score, treatment modality, type of surgical intervention, types and treatments of associated nonneurosurgical pathologies, total experienced CT count, total

How to cite this article: Sarica C, Yucetas SC, Kilinc S, et al. Neurosurgical aspects of falls from flat-roofed houses. Marmara Med J 2021; 34(1):29-32. doi: $10.5472 /$ marumj. 860214 
days of hospitalization in the intensive care unit (ICU) and in the ward, prognosis, and follow-up.

Data for the Turkish population were obtained from the Turkish Statistical Institute [4]. The catalogs studied were as follows: 1590 population of provinces by years (2000-2017) and 1587 population of province/district centers and towns/villages by years and sex (1927-2017). Temperature data were acquired from Accuweather Inc. (PA, USA) [5]. Radiological data were obtained from the reports of a full-time radiology consultant, and the images were double-checked by two consultant neurosurgeons.

\section{Statistical Analysis}

Quantitative variables were compared using the MannWhitney $U$ test. Correlations between quantitative variables were estimated using Spearman coefficient. IBM SPSS Statistics
V21.0 was used for the statistical analysis, and $P$ value less than 0.05 was considered statistically significant.

The study was reviewed and approved by Adiyaman University Institutional Review Board (document no:176-21).

\section{RESULTS}

\section{Incidence and demographics}

A total of 31 patients (19 males, 12 females) (Table I) who fell from flat-roofed houses were admitted to the emergency department and consulted to the neurosurgery department. The mean age of all patients was 16.8 (range: $1-78$ ) years; $77 \%$ (n: 24$)$ were below 18 years. The overall population of Adiyaman in 2017 was 615,076 , giving a crude rate of 5 new cases of falls from flat-roofed houses per 100,000 cases (Table II).

Table I. Clinical characteristics of patients with falls from flat-roofed houses

\begin{tabular}{|c|c|}
\hline & No. of Cases (\%) \\
\hline \multicolumn{2}{|l|}{ Demographics } \\
\hline Total number of patients & 31 \\
\hline Male & $19(61 \%)$ \\
\hline Female & $12(39 \%)$ \\
\hline Mean age (range) & $16.8(1-78)$ \\
\hline Pediatric & $24(77 \%)$ \\
\hline Adult & $7(23 \%)$ \\
\hline \multicolumn{2}{|l|}{ Findings on Initial CT } \\
\hline Cranial & $25(81 \%)$ \\
\hline Isolated Linear Fracture & 12 \\
\hline Frontal & 8 \\
\hline Parietal & 2 \\
\hline Occipital & 2 \\
\hline Isolated Depressed Fracture & 4 \\
\hline Parietal & 2 \\
\hline Frontal & 2 \\
\hline Linear Fracture + EDH & 3 \\
\hline Temporal & 2 \\
\hline Frontal & 1 \\
\hline Linear Fracture + SDH & 1 \\
\hline Frontal & 1 \\
\hline Linear Fracture + Contusion & 2 \\
\hline Temporal & 1 \\
\hline Occipital & 1 \\
\hline SAH & 2 \\
\hline Diffuse axonal injury & 1 \\
\hline Spinal & $6(19 \%)$ \\
\hline Compression fracture & 5 \\
\hline Burst fracture & 2 \\
\hline Number of patients who underwent surgery & $5(16 \%)$ \\
\hline Number of patients who underwent spine surgery & $3 / 6(50 \%)$ \\
\hline Number of patients who underwent cranial surgery & $2 / 25(8 \%)$ \\
\hline Mortality & 0 \\
\hline Associated Pathologies & 8 \\
\hline Extremity Fracture & 5 \\
\hline Ocular Trauma & 1 \\
\hline Rib Fracture & 1 \\
\hline Retroperitoneal Hematoma & 1 \\
\hline
\end{tabular}

EPH: Epidural hematoma, SDH: Subdural hemorrhage, SAH: subarachnoid hemorrhage 
The fall incidence for Adiyaman was calculated by dividing the number of new cases that were prospectively collected in 2017 by the population of Adiyaman in 2017. The two studies that give information about falls from flat-roofed houses in Diyarbakir were conducted between January 1997 and May 2001 and between January 2005 and December 2008, respectively. The mean yearly incidence was calculated by dividing the total number of cases in 4.4 and 4 years, respectively, by the average population in the given time period. The obtained rates are divided by 4.4 and 4 , respectively, to get a mean yearly incidence. Given the lack of yearly case numbers in the given studies, the calculated mean yearly incidence is not an exact number but a close (Table II).

Table II. Crude rate of falls from flat-roofed houses

\begin{tabular}{|l|c|c|c|}
\hline & Adiyaman & Diyarbakir [1] & Diyarbakir 2 [8] \\
\hline Population in 2017 & 615,076 & - & - \\
\hline $\begin{array}{l}\text { Average population between } \\
\text { 1997-2001* }\end{array}$ & - & $1,328,064$ & - \\
\hline $\begin{array}{l}\text { Average population between } \\
\text { 2005-2008 }\end{array}$ & - & - & $1,452,000$ \\
\hline Total falls & N/A & 1643 & 1056 \\
\hline Neurosurgical consultancy & 31 & 839 & N/A \\
\hline Rate for $100.000^{\mathrm{a}}$ & - & $28.1^{* *}$ & 18.1 \\
\hline Rate for $100.000^{\mathrm{b}}$ & 5.0 & $14.3^{* *}$ & - \\
\hline
\end{tabular}

N/A: Not available ${ }^{*}$ Average population calculated by the population in 2000 and 2001 because of incomplete data before 2000. ${ }^{*}$ May be slightly higher because the study comprises only winter months in 2001, which may have a lower patient density compared to summer months. ${ }^{a}$ For falls in total population in a year. ${ }^{b}$ For falls requiring neurosurgical consultancy in the total population in a year.

\section{Characteristics of fall incidents}

All incidents occurred in villages, and all were accidents (no suicidal intent was detected). Twelve of the patients (38\%) landed on concrete and the remaining on soil. The mean height of the falls was $2.8 \pm 1.0(2-6) \mathrm{m}$. There was a significant positive correlation between monthly highest temperature and the number of cases $(r=0.6, p=0.03)$. The number of cases was significantly higher in months with temperature above $33^{\circ} \mathrm{C}$ (June-September) than those below $33^{\circ} \mathrm{C}(\mathrm{p}=0.006$, Table III).

Table III. Distribution of cases according to months

\begin{tabular}{|l|c|c|c|c|c|c|c|c|c|c|c|c|}
\hline 2017 & Jan & Feb & Mar & Apr & May & June $^{*}$ & July $^{*}$ & Aug $^{*}$ & Sept $^{*}$ & Oct & Nov & Dec \\
\hline $\begin{array}{l}\text { Highest } \\
\begin{array}{l}\text { Temperature } \\
\left({ }^{\circ} \mathrm{C}\right)\end{array}\end{array}$ & 12 & 18 & 20 & 26 & 33 & 39 & 41 & 43 & 40 & 27 & 21 & 18 \\
\hline No. of cases & 2 & - & 1 & - & - & 4 & 7 & 6 & 6 & 1 & 3 & 1 \\
\hline
\end{tabular}

The number of cases is significantly higher in months with the highest temperature (above $33^{\circ} \mathrm{C}$ ) and marked with an asterisk $\left.{ }^{*}\right)(p=0.006)$.

\section{Clinical data}

The results are summarized in Table I. Twenty-five patients (80\%) had a cranial injury; however, no patient simultaneously had a cranial and a spinal injury. The initial GCS score was $14.2 \pm 1.2$
(10-15). The most common pathology on initial CT was isolated linear fracture $(38 \%)$, and the most commonly fractured bone was the frontal bone. One patient simultaneously had a burst and compression fracture on the T11 and L2 levels, respectively. Three patients had a multiple level spinal injury, and T12 was the most commonly affected vertebra level in three patients. Five patients experienced an extremity fracture (3 upper, 2 lower extremity), and no surgeries were performed for the associated anomalies. The overall mortality rate was $0 \%$. Five patients (16\%, 2 cranial, 3 spinal) underwent surgery. Among them, two underwent "single-level decompression (laminectomy + foraminotomy) + fusion (2 levels up, 2 levels down)" on day 0 of the incident, and one patient underwent "one-level kyphoplasty" for the refractory lumbar pain on the third month after the incident. For cranial injuries, a child underwent surgery for the depressed frontal fracture for cosmetic reasons, and another child with an initial GCS score of 12/15 underwent an emergent surgery for the temporal fracture + epidural hematoma. The mean CT count during hospitalization was $2 \pm 1.06$ (1-5). Twenty-seven patients (87\%) were hospitalized, among which $13(41 \%)$ had an ICU stay. The mean stay in the ward and ICU was $5.6 \pm 5.6(1-22)$ and $2.4 \pm 2.0(1-8)$ days. All patients were discharged with full recovery, except one adult woman who fell when she went up to the rooftop to collect some dried food and fell after being butted by a goat. She was paraplegic before and after the surgery, and no functional recovery was observed on her follow-up in five months. All patients were noted to have none or acceptable symptoms in their first outpatient clinic visit on the first month of the fall. The patient who underwent a kyphoplasty has had a decreased visual analog scale score from $6 / 10$ (preoperative) to $2 / 10$ (on postoperative 3 months).

\section{DISCUSSION}

Unintentional injuries are among the top 10 death causes in the USA and are responsible for 5\% of overall deaths [6]. Falls can cause serious injuries with high morbidity and mortality; they comprise $21 \%$ of all major trauma mechanisms in a recent epidemiological study [7]. Published articles regarding the epidemiological features of falls from flat-roofed houses in Southeastern Turkey are very few $[1,8,9]$. Unfortunately, incidence data about these falls in Adiyaman in the past years is not available; therefore, this is one of the major limitations that prevent from making a more accurate comparison between the present and past years. For comparison, we used two studies conducted in the Diyarbakir province between January 1997 and May 2001 and between January 2005 and December 2008 $[1,8]$. We excluded the study conducted in the Batman province as it covered only a seven-month period, which is not adequate for a yearly incidence calculation [9]. The comparison of the incidence of the falls from flat-roofed houses in the Diyarbakir and Adiyaman provinces are acceptable because they are close neighbors and have similar lifestyles, traditions, and demographic characteristics for centuries.

The epidemiological data is summarized in Table II. Yagmur et al., have reported 1.643 patients who fell from flat-roofed 
houses between January 1997 and May 2001 [1]. We calculated a mean yearly incidence of 28.1 for overall patients and 14.3 for patients with neurosurgical pathologies. Icer et al.,reported 1,056 falls between January 2005 and December 2008 in Diyarbakir, giving a mean yearly incidence of 18.1 [8]. Another limitation is that these studies conducted in Diyarbakir do not provide the exact number of patients in each year during the study period; therefore, our calculations are not exact but a close approximation. In regard of this data, we can obviously comment that the incidence of falls from flat-roofed houses decreased approximately 1.5 times in Diyarbakir in 12 years (between 1997 and 2008). The incidence for neurosurgical patients in 2017 in our study was almost three times lower than that in the study conducted in Diyarbakir (Table II). We identified three possible reasons for a low incidence in our study:

(1) In 2000, Turkey had a population of $67,803,927$, among which $23,797,653$ (35\%) were living in villages. On the other hand, in 2017 , only $6,049,393(7 \%)$ among $80,810,525$ people were living in villages [4]. There is a significant drop in the village population in Turkey, where most of the fall-related injuries occur.

(2) Studies that aim to emphasize the importance and identify the risk and preventive factors (compulsory building of pitchroofed houses or of a barrier around flat roofs, beds, and/or roof stairs, locking of roof door to prevent children from using the roof as a playground) of such situations might create public awareness for the prevention of such accidents $[1,8,9]$.

(3) The use of air conditioning may have been increased over the past 20 years in Turkey.

Falls from flat-roofed houses were the second leading cause of death from accidental injuries in Diyarbakir, accounting for more than 117 deaths (33.7\% of 329 traumatic deaths) during 1997 [1]. We did not face any mortality during our study period, possible because of a relatively lower mean height of fall, lower percentage of patients that fell on concrete, and lack of any suicide attempts.

\section{Conclusion}

Although, falls from flat-roofed houses remain an important cause of morbidity, their current incidences in Adiyaman in Southeastern Turkey is currently not as high as that 20 years ago in Diyarbakir, a neighboring city with a similar lifestyle. Possible precautions may further decrease the incidence of such fallrelated injuries to more acceptable rates.

\section{Acknowledgements}

Preparation for publication of this article is partly supported by Turkish Neurosurgical Society.

\section{Compliance with Ethical Standards}

Ethical Approval: The study was reviewed and approved by Adiyaman University Institutional Review Board (document no:176-21).

Financial Support: This research did not receive any specific grant from funding agencies in the public, commercial, or notfor-profit sectors.

Conflict of Interest: None of the authors have any conflict of interest to declare regarding the article.

Author Contributions: Concept and Design - CS, SCY, NU, AO; Supervision - AO; Data Collection and Processing - CS, SCY, SK, LTS, ID, TO, ArO, NU; Analysis and Interpretation CS, OAS; Literature Search - CS, ArO, TO; Writing Manuscript - CS, OAS; Critical Review - SCY, NU, SK, AO. All authors approved the final version of the article.

\section{REFERENCES}

[1] Yagmur Y, Guloglu C, Aldemir M, Orak M. Falls from flatroofed houses: a surgical experience of 1643 patients. Injury 2004;35:425-8. doi: 10.1016/S0020-1383(03)00198-0

[2] Rudelli BA, Silva MV, Akkari M, Santili C. Accidents due to falls from roof slabs. Sao Paulo Med J 2013;131:153-7. doi:10.1590/1516-3180.2013.131.3479

[3] Umerani MS, Abbas A, Sharif S. Traumatic brain injuries: experience from a tertiary care centre in Pakistan. Turk Neurosurg 2014;24:19-24. doi: 10.5137/1019-5149.JTN.708012.1

[4] Turkish Statistical Institute. http://www.tuik.gov.tr/. Accessed: 1 March 2019

[5] Accuweather Inc. https://www.accuweather.com/. Accessed: 1 March 2019

[6] Johnson NB, Hayes LD, Brown K, et al. CDC National Health Report: leading causes of morbidity and mortality and associated behavioral risk and protective factors-United States, 2005-2013. MMWR Suppl 2014;63:3-27.

[7] Chen SS, Bosson N, Gausche-Hill M, Gorospe DD, Tadeo RE. The evolution of trauma in Los Angeles county over more than a decade. J Public Health Manag Pract 2019;25:E17-E20. doi: 10.1097/PHH.000.000.0000000745

[8] Icer M, Guloglu C, Orak M, Ustundag M. Factors affecting mortality caused by falls from height. Ulus Travma Acil Cerrahi Derg 2013;19:529-35. doi: 10.5505/tjtes.2013.77535

[9] Al B, Yildirim C, Coban S. Falls from heights in and around the city of Batman. Ulus Travma Acil Cerrahi Derg 2009;15:141-7. 